Published in final edited form as:

Ann N Y Acad Sci. 2018 September ; 1428(1): 208-220. doi:10.1111/nyas.13637.

\title{
Neural predictors of eating behavior and dietary change
}

\author{
Nicole R. Giuliani ${ }^{a, b}$, Junaid S. Merchant ${ }^{c}$, Danielle Cosme ${ }^{b, d}$, and Elliot T. Berkman ${ }^{b, d}$ \\ aDepartment of Special Education and Clinical Sciences, University of Oregon \\ ${ }^{b}$ Center for Translational Neuroscience, University of Oregon \\ 'Department of Psychology, Georgetown University \\ dDepartment of Psychology, University of Oregon
}

\begin{abstract}
Recently, there has been an increase in the number of human neuroimaging studies seeking to predict behavior above and beyond traditional measurements such as self-report. This trend has been particularly notable in the area of food consumption, as the percentage of people categorized as overweight or obese continues to rise. In this review, we argue that there is considerable utility in this form of health neuroscience, modeling the neural bases of eating behavior and dietary change in healthy, community populations. Further, we propose a model and accompanying evidence indicating that several basic processes underlying eating behavior, particularly reactivity, regulation, and valuation, can be predictive of behavior change. We also discuss future directions for this work.
\end{abstract}

\section{Keywords}

eating; dieting; behavior change; brain-as-predictor

\section{Introduction}

The question, "who will be successful in dieting?" is of interest to laypeople, interventionists, and scientists alike. In this article, we argue that an effective way to answer that question is to build and test a model of the mechanisms by which eating behavior changes, and then interrogate those mechanisms using innovative techniques. We present such a model and evidence indicating that several basic processes underlying eating behavior, particularly reactivity, regulation, and valuation, can be predictive of behavior change. This model is based in health neuroscience, which investigates the interplay between the brain and physical health. ${ }^{1}$ Specifically, these processes act on the individual level, impacting physical health via direct and interactive effects on the brain, as well as via

\footnotetext{
Address correspondence to: Nicole R. Giuliani, Special Education and Clinical Sciences, College of Education, 5261 University of Oregon, Eugene, OR 97403-5261, giuliani@uoregon.edu; Elliot T. Berkman, Department of Psychology, 1227 University of Oregon, Eugene, OR 97403, berkman@uoregon.edu.

Competing interests

E.T.B. is manager of Berkman Consultants, LLC, a consulting firm that specializes in motivation and behavior change. No other author declares a competing interest.
} 
mediating processes that influence and are influenced by the brain. ${ }^{1}$ We close by laying out future directions for eating behavior change and the prediction of change more generally.

\section{Motivation for this review}

A considerable amount of knowledge about how the human brain responds to food stimuli has accumulated even since the recent emergence of health neuroscience. ${ }^{1-3}$ Building on this initial wave of information, in subsequent studies researchers have started to explore whether and how functional neural activation in response to food cues predicts later food intake (e.g., Refs ${ }^{4,5}$ ). This pattern in health neuroscience mirrors events in social and affective neuroscience. In that literature, the first generation of studies established the basic pattern of neural activity with a process (e.g., anticipation of monetary reward) and then later studies leveraged that initial information to test hypotheses about its predictive validity (e.g., does it predict gambling?). The latter approach has been referred to as the "brain-aspredictor" approach. ${ }^{6}$ Using human neuroimaging not only for brain mapping, but also for prediction of important outcomes, has been described as an important "humanitarian" goal. ${ }^{7}$ With that goal in mind, our overarching aim here is to review and organize the recent neuroimaging literature on eating behavior change. Establishing functional and structural neural factors that predict eating and its change can uncover additional mechanisms of change, with the ultimate purpose of informing the design and revision of behavior change interventions. Specifically, in this paper we review a carefully selected set of studies representing the extant literature on neural predictors of food consumption and dietary change in community populations.

Because we are interested in establishing the neural predictors of eating behavior, we focus specifically on dietary change, and not necessarily weight change. A growing body of work focuses on how individual patterns of brain activity predict weight change (e.g., Refs ${ }^{8-10}$ ). This is valuable information, especially given the increase in overweight and obesity worldwide. ${ }^{11}$ However, eating per se is understudied in the health neuroscience literature and is related to health outcomes (e.g., heart disease, diabetes, cancer ${ }^{12}$ ) above and beyond the effects of weight. For example, consumption of foods rated high in either glycemic index or glycemic load is associated with increased risk of developing several types of cancers (e.g., colorectal, endometrial, pancreatic), even in the absence of overweight and obesity. 13-16 To this end, we focus this review on the neural predictors of food consumption and dietary change, separate from weight change. Furthermore, while it remains an open empirical question if the neural predictors of dietary improvement are the inverse of dietary deterioration (i.e., the process by which the contents of one's diet become less healthy), this review focuses solely on positive dietary change. Lastly, by focusing on community populations (as compared to individuals who have been diagnosed with conditions characterized by non-typical eating patterns such as eating disorders), the work covered in this review connects to the larger literature on population-level behavior change as part of health psychology and health neuroscience.

\section{Theoretical framework}

Historically, the studies that have investigated neural predictors of eating behaviors in community populations have differentiated liking, wanting, and craving for food (which we 
include here as components of reactivity, defined below; Figure 1a) from regulation of that desire (Figure 1b). As shown in Figure 1, regulation is traditionally thought to decrease reactivity to the food cue, and thus decrease the likelihood of consumption. This review also follows this conceptualization to reflect how the literature has evolved to date. However, we emphasize that this dual-process framework, which pits "hot" craving with "cold" regulation (seen also in domains such as executive function, ${ }^{17,18}$ decision-making, ${ }^{19,20}$ the ReflectiveImpulsive Mode ${ }^{21}$ ), may artificially narrow the focus of research in this area, causing the field to ignore other, potentially important factors that don't fit squarely into one bin or the other. As such, we also review evidence related to one such factor, subjective value. A value accumulation process integrates the value of a range of choice attributes, including social influence (e.g., norms, peer pressure), self-related processes (e.g., goals, identity), and primary and secondary reward value, and moderates the degree to which reactivity and regulation influence behavior. This process is visualized in Figure 1c. We conceptualize eating as one of many potential target behaviors that could be examined in this framework. For example, physical activity and other health-promoting behaviors would fit just as well into our framework, with cues motivating the unhealthy choice as reactivity cues, and alternate healthy and unhealthy behavioral choices shown in Figure 1.

\section{Using reactivity to predict food consumption}

A logical starting point when investigating the predictors of dietary change are the factors that promote unhealthy eating in the first place. The appetitive desire to consume a food, often referred to as 'craving,' is a type of reaction to food, defined as the "conditioned response to food that is frequently accompanied by increased salivation, physiological arousal, and neural activity in regions such as the ventral striatum."22 This broad definition of reactivity includes hunger motivation for food, which involves a larger recruitment of attentional resources compared to liking and wanting. ${ }^{23}$ It also encompasses the affective/ hedonic processes that generate liking, the pleasure or anticipated pleasure derived from food consumption, as well as the motivational process that generates wanting, the motivation to consume a food. ${ }^{24-26}$ These processes can be triggered from the sensory experience of an external food cue or the internal experience of imagining a food cue, both of which are hypothesized to rely upon the same neural network. ${ }^{27}$

As noted in the Boswell and Kober (2016) definition above, reactivity to food cues classically recruits brain regions involved in reward processing (see Figure 2), including the striatum and orbitofrontal cortex (OFC). ${ }^{22}$ The striatum is a subcortical structure that receives excitatory input from frontal cortical regions and dopaminergic input from midbrain substantia nigra, and projects inhibitory connections back to globus pallidus. As such, the striatum is centrally involved in influencing motor and cognitive aspects of behavior. ${ }^{28}$ The dorsal striatum (DS) is involved in more cognitive and sensorimotor functions, whereas the ventral striatum (VS), which consists primarily of the nucleus accumbens (NAcc), supports affective and motivational processing such as that elicited by food. ${ }^{29}$ The VS also receives extensive projections from ventral frontal regions, including the OFC. ${ }^{28}$ The OFC is critically involved in sensory integration, modulating autonomic reactions, representing experienced and expected reward value, and supporting emotional and reward-related behaviors. ${ }^{23}$ Food cue-reactivity also recruits brain regions known to underlie object 
recognition, gustatory, and somatosensory processing like the lateral occipital gyrus, primary gustatory cortex (comprised of the anterior insula and frontal operculum), and primary somatosensory cortex respectively (see Refs 3,30 for reviews).

Interestingly, much of this work has focused on food cue-reactivity during functional magnetic resonance imaging (fMRI), sometimes after exposing participants to the actual food. For example, chocolate cue-related activity in the caudate, a structure within the dorsal striatum, was found to predict later chocolate consumption in a group of participants who were exposed to chocolate as part of a "taste test" before the scan. ${ }^{31}$ This activity was specific to the exposure group compared to the control group, and predicted consumption above and beyond self-reported craving. ${ }^{31}$ Similarly, activity in the medial OFC, amygdala, insula, and NAcc while viewing high-calorie food while sated predicted higher-fat food choices after an fMRI scan. ${ }^{32}$ Lastly, in the considerable body of work investigating brain activity during milkshake consumption, a few studies have investigated how activity during consumption predicts later ingestive behavior. In one, midbrain and medial OFC activity related to milkshake tastes during an fMRI scan positively predicted later ad libitum milkshake consumption. ${ }^{33}$ Another found that variability in NAcc activity to milkshake consumption was related to dietary disinhibition and variability in ad libitum food intake, which provided an avenue for understanding variability in eating behavior. ${ }^{34}$

Following Berridge's theoretical distinction of liking and wanting ${ }^{25}$, research investigating the neural correlates of food reactivity has recently begun to differentiate between brain regions associated with liking (desirability), wanting (hereafter referred to as craving), and behavior (actual eating). In this model, craving recruits more of the reward network than liking, ${ }^{35}$ but the overlapping definitions of these constructs and the underlying neural structures have made it challenging to experimentally separate liking from craving. ${ }^{36}$ However, recent work has found that self-reported craving for highly-processed foods is dissociable from the liking of those foods, with craving predicted by self-reported food addiction and liking associated with body mass index. ${ }^{37}$ In addition, Lawrence et al. (2012) found that food cue-reactivity in the ventromedial prefrontal cortex (vmPFC, which overlaps with and is often identified as OFC) positively correlated with self-reported food craving, but only NAcc activity during food cue presentation positively predicted later consumption over and above self-reported hunger and craving. ${ }^{38}$ This pattern of results indicates that, if defined correctly for participants, there may also be dissociations among brain regions involved in liking and craving when it comes to predicting food consumption. Furthermore, other work has shown that vmPFC activity in response to health messaging predicts behavior change above and beyond self-report. ${ }^{39}$ Together, these findings suggest that food-cue related activity in the NAcc indexes baseline urges that predict eating behavior, whereas the vmPFC may be involved in the more evaluative aspects of eating behavior, which include motives such as self-reported craving and dieting. While much remains to be done, this work supports continued efforts by theorists and researchers to differentiate between liking and craving evaluations of food stimuli and their neural substrates when predicting later consummatory behaviors.

Despite the body of work indicating that neural reactivity predicts food consumption, there remains significant ambiguity about the causes of this relationship. It may be just as likely 
that habitual patterns of food consumption affect processing of food cues at a neural level. Indeed, habitual consumption of high-calorie foods has been found to affect neuropeptide expression in the hypothalamus, ${ }^{40}$ suggesting that excess consumption of high-calorie foods may result from both the hedonic and homeostatic effects of fat and sugar. This can be seen in Figure 1a, where the reactivity to a desired unhealthy food elicits the choice behavior of consuming that food, which then feeds back to increase reactivity to those food cues. However, very few studies have addressed the enduring effects of poor diet in nonoverweight and obese individuals, especially as it relates to altered neuropeptide expression, BOLD reactivity, and food consumption. Future studies would benefit from employing neuroimaging at multiple time points in order to identify the causal direction of the relationship between diet and brain activity in healthy, community populations.

\section{Using regulation to predict food consumption}

Although we perpetually process and react to the food cues pervading our environment, as humans we also possess the ability to regulate our desires. Regulation, as defined in the affective science literature, refers to active attempts to manage one's emotional states. ${ }^{41}$ When applied to eating behavior, regulation can influence the affective states of liking and craving that precipitate food consumption. Longitudinal studies have shown that individual differences in self-control, the ability to regulate behavioral, emotional, and attentional impulses when they conflict with long-term goals, ${ }^{42}$ protect against overweight status over time ${ }^{43,44}$ Indeed, much of this work has focused on weight change in obesity. ${ }^{45}$ For example, activity in prefrontal cortex, which is central to the inhibition of food reward, is negatively correlated with long-term weight change among obese women. ${ }^{46}$ In comparison, relatively few studies have investigated how regulation-related brain activity predicts food consumption in normal-weight individuals.

\section{Food-specific regulation}

Before diving into this body of work, we want to acknowledge that there are many ways to operationalize the concept of regulation with respect to control of food desires. In these studies, the concepts of liking and craving are generally combined. Both concepts can be thought of as affective states, like stress and mood (see Ref ${ }^{47}$ ). As such, we and others have built upon the large literature on emotion regulation to demonstrate that, similar to emotion, craving can be down-regulated using cognitive techniques (e.g., Refs ${ }^{48-53}$ ). In particular, reappraisal can be used in this context to think about a craved food in a different way so as to reduce its desirability. Across a series of studies, this strategy has been found to effectively reduce food craving compared to passive viewing (e.g., Refs $48,51,53$ ). Learningbased models of behavior illustrate how visual exposure to pictures or videos of food can increase eating behavior through conditioned physiological responses that are typically paired with food cues (see Ref ${ }^{22}$ ). Reappraisal might work by disrupting this cue-response pairing. For example, there is initial evidence that reappraisal training modulates cuereactivity to energy dense foods, resulting in increased activity in regulation-related regions, such as the inferior frontal gyrus (IFG), pre-to-post intervention. ${ }^{54}$ This hypothesis is further supported by research on several psychological treatments (e.g., Cognitive Behavioral 
Therapy applied to food cues), which have been most commonly tested in the context of pathological eating behaviors (e.g., bulimia nervosa). ${ }^{55}$

The neural correlates of cognitive reappraisal of emotion have been well-documented in the literature (see Ref ${ }^{56}$ for a meta-analysis). Reappraisal elicits extensive recruitment of regions commonly observed in executive function and cognitive control tasks such as the dorsolateral prefrontal cortex (dlPFC), dorsal anterior cingulate cortex (dACC), IFG, ventrolateral prefrontal cortex (vlPFC), and posterior parietal cortex (PPC; see Figure 2). These brain regions support the component processes involved in reappraisal, including inhibitory and cognitive control, response selection and inhibition, holding reappraisals in mind, and reflecting on the meaning of changing emotional states. ${ }^{57-59}$ Work from our group shows that, across multiple populations of community participants, reappraisal of food craving elicits activity in these same regions. ${ }^{49,60}$

While much of this section has focused on reappraisal, other approaches to down-regulate the craving of food stimuli have also been explored. In particular, regulatory response training refers to the training of behavioral response to low-calorie food stimuli and the inhibition of responses to high-calorie food stimuli. ${ }^{61}$ Recent work has demonstrated that this approach leads to devaluation of foods paired with the inhibitory response and reduction in consumption of these foods. ${ }^{62-68}$ Moreover, a recent pilot study demonstrated that response training leads to reductions in PPC, DS, and insula activity in response to highcalorie foods that were paired with inhibition training. ${ }^{61}$ Though this study measured changes in brain activity as a result of training, and did not directly measure food consumption, future work can overcome these limitations.

\section{Domain-general regulation}

Due to the extensive engagement of cognitive control networks in reappraisal, it is possible that other cognitive processes that engage these same regions (e.g., inhibitory control) might predict dietary behavior. This line of reasoning would suggest that regulation may be treated as a general executive process that is not specific to affect, but instead operates on a broad range of targets, and thus can be indexed by domain-general measures. ${ }^{64,69-71}$ For example, Hofmann et al. (2009) found that performance on tasks that measure inhibitory control, affective regulation, and executive attention predict eating behavior (candy consumption), even though performance on the tasks did not relate to each other. ${ }^{71}$ This suggests that there might be several basic executive processes that independently contribute to eating behavior. A recent review highlights the reliability and generalizability of tasks indexing executive function and cognitive control, all of which engage lateral prefrontal regions, in predicting eating behavior. ${ }^{72}$ However, one study uncovered an interaction between body mass index (BMI) and food specificity in predicting in inhibitory control, such that high BMI individuals showed less impulse control during a food-specific versus general stop-signal task, while low BMI individuals demonstrated no such distinction. ${ }^{64}$ Together, these findings suggests that domain-general neurocognitive measures may be used to predict eating behavior among individuals within the normal BMI range, but the predictive validity of these measures requires further scrutiny among individuals with elevated BMI. 


\section{Predicting behavior change}

In comparison, relatively few studies have investigated how regulation-related brain activity in response to food relates to behavioral change. Reappraising food craving recruits a very similar network to that involved in other targets of cognitive reappraisal, including the IFG, dACC, and dIPFC ${ }^{49}$ suggesting that the regions are key nodes for regulation. Supporting this conclusion with a complementary method, increasing activity in the dlPFC with transcranial direct current stimulation (tDCS) has been found to reduce self-reported craving for food stimuli. ${ }^{73}$ Because tDCS can be used manipulate (as opposed to merely observe) activity, this last study suggests that the dIPFC has a causal effect on food craving and its associated brain network.

Several studies have investigated mediators and moderators of the effect of regulation on food intake. This research explores the questions of how (mediators) and under what conditions (moderators) regulation can be effective in altering intake. In a direct comparison of brain activity in the regulation network under conditions of passive monitoring or restriction of the consumption of a craved, unhealthy food, we found that reappraisal-related brain activity significantly positively predicted subsequent food consumption, but only under restriction conditions. ${ }^{5}$ This pattern of results indicates that the neural networks underlying reappraisal, especially the dIPFC, may support successful behavior change when people are deliberately attempting to restrict their eating. As shown in Figure 1b, reappraisal and subsequent dietary change may function via modulation of reward-related activity, such that explicit self-control during food cue exposure is associated with a reduction of VS activity by the lateral prefrontal cortex. ${ }^{51,74,75}$ Specifically, the dIPFC sends excitatory signals to the NAcc, which sends inhibitory signals to the globus pallidus, a region centrally involved in voluntary behavior. Incidental activity (i.e., during food cue viewing without explicit regulation instructions) in the reappraisal network also predicts attention to health cues and subsequent food choice. ${ }^{3,31}$

Recent theories have posited that food consumption may not result from reactivity- and regulation-related brain activity acting independently or in direct competition, but rather from a balance between the two. Overeating has been linked to the interaction of increased food reactivity and reduced inhibitory control. ${ }^{76,77}$ Similarly, a combination of strong implicit preferences for snack foods and low trait self-control has been found to predict increased food intake. ${ }^{78}$ Therefore, dietary change may result from altering the balance of these two systems.

\section{Subjective valuation as a promising process for predicting behavior change}

The research presented thus far has evolved from the affective science literature, which focuses on affective and regulatory predictors of food consumption and dietary change. A related, yet distinct framework for understanding eating behavior comes from the decisionmaking and neuroeconomics literature, which examines the dynamic computations made by the brain during value-based decision making. ${ }^{79}$ For example, attending to health aspects of food stimuli has been found to affect value signals in the vmPFC, which acts via regulationrelated brain activity in the dIPFC. ${ }^{80}$ While the reactivity/regulation and value frameworks are partially overlapping, they have complementary strengths and differing implications for 
predicting behavior, so there is value in considering them separately. Additionally, the frameworks are not mutually exclusive, so it is possible for future research to leverage aspects of both within the same study to maximize predictive power. ${ }^{81}$

Neuroeconomics is an emerging interdisciplinary field that brings together a rich history of experimental decision paradigms from behavioral economics, formal models of subjective experience from cognitive science, and computational models of learning from psychonomics. ${ }^{79}$ These approaches can guide psychological and neuroscientific investigations by providing sophisticated models that link neural and behavioral data, as well providing novel, testable models of what predicts changes in eating behavior. For example, as noted at the outset of this review, reactivity and regulation together comprise a dualprocess framework that distinguish two types of choice behavior: "cold," deliberate, regulatory decision making that competes with "hot," instinctive reactions to food-cues. ${ }^{82}$ This framework suggests that eating behavior is ultimately predicted by one of these processes "winning," and is supported by research showing distinct brain systems underlying each process. This can be seen in Figure 1b, where the influence of regulation reduces the influence of reactivity on food choice behavior.

However, an alternative perspective from neurocomputational approaches suggests that these two behaviors (here shown as healthy and unhealthy eating) are assigned values unique to the individual, which are then integrated in the vmPFC during the selection of eating behavior. ${ }^{83,84}$ In these models, the "hot" and "cold" processes do not directly compete with one another per se, but rather contribute jointly - along with other choice features - to a unified integration process that drives food choice. One implication of this kind of model is that one way to change eating behavior is to amplify the factors that contribute positive value to healthy options. Those factors are not necessarily "cold" processes that would downregulate temptation, but also a variety of options that would up-regulate desire for or value of healthy food such as social pressure, representations of long-term health outcomes, and reminders of important core values or aspects of one's identity. ${ }^{85}$ Value integration models, therefore, do not deny the distinction between hot and cold processes, but rather reject the notion that there is a one-to-one mapping between hot-cold and unhealthy-healthy.

The differences between the two frameworks are subtle, but the value integration approach offers several advantages in terms of prediction. All of them revolve around the increased precision of value-integration models about the neural and computational processes involved in choice relative to alternatives (e.g., dual-process or older utility models). For example, valuation models better explain how shifts in attentional focus toward health cues improve dietary choice. ${ }^{80}$ Indeed, the specific neurocomputational processes that underlie the effect of visual attention on the value integration process are increasingly well understood. ${ }^{86}$ Also, valuation models suggest an empirical tool to model, predict, and characterize the online accumulation of value during food choice ${ }^{87}$ Finally, studies deploying a value-based choice paradigm have shown that activity in the vmPFC during choice tracks closely with objective measures of food value (caloric density), and predicts food choice to a greater degree than subjective assessments of food value. ${ }^{88}$ There is evidence that valuation-related activity can prospectively predict behavior change in a variety of domains (e.g., smoking cessation, 
market forecasting ${ }^{39,89}$ ), though this predictive effect has not yet been demonstrated in the food domain.

Another advantage of the value-based decision making approach is that it allows researchers to apply the vast literature of choice anomalies to the study of food intake. ${ }^{85} \mathrm{~A}$ highlystudied example is delay discounting, ${ }^{90}$ which refers to the phenomenon where people tend to discount the value of delayed outcomes (e.g., long-term health) as compared to immediate outcomes (e.g., tasty treats). Indeed, Dassen and colleagues demonstrated that healthy eating is positively associated with consideration of future consequences of food intake, and negatively associated with consideration of immediate food consequences. ${ }^{91}$ Diminishing marginal utility is another anomalous decision-making phenomenon that refers to the continued reduction in value of a consumed item, such as a desirable food, as more of the item is consumed. ${ }^{92}$ Interestingly, this is observed even when a person simply imagines eating the food repeatedly, ${ }^{27}$ and has opposite behavioral predictions than the neuropeptide feedback research described in the reactivity section above. ${ }^{40} \mathrm{~A}$ final example is the decoy effect ${ }^{93}$ which refers to the phenomenon whereby people change their previously-consistent preference between two options (e.g., favoring a $\$ 5$ burger over a $\$ 5$ soup-salad combo) when presented with a third option that is never chosen (e.g., a $\$ 5$ small a la carte salad). Together, the wealth of research on choice anomalies unlocks new avenues for the development of new dietary interventions. Moreover, because many of these phenomena have been studied with neuroimaging, this work provides testable hypotheses about the brain processes involved.

Lastly, the focus on value provides a flexible, integrative framework for looking at the neural predictors of dietary change. For instance, the dual-process, reactivity/regulation model detailed in the first two sections can be considered to be a specific subset of the large set of possible value attributes that drive food choice. The valuation perspective does not deny the importance of "hot" hedonic value and "cold" regulatory processes, but also allows third, fourth, etc., processes to also play a role. For example, it is unclear whether and how social factors such as norms fit into the strict dual-process perspective, though there is now good evidence that social norms influence food choice by altering the value of foods to be more consistent with the apparent preferences of peers. ${ }^{94}$ As highlighted above, an advantage afforded by the value-based decision making perspective on food consumption is the integration and operationalization of the many component processes involved in consummatory behavior, as seen in Figure 1c. While many fields of research have struggled with the reliance on self-report in examining the predictors of eating behavior, neuroeconomic researchers are among those who have provided objective, brain-based metrics to measure value, as well as providing an ecologically valid experimental framework for examining food-based decision making. Although current work focuses primarily on food choice within an experimental paradigm, this framework could be extended in the future to predict individual differences in dietary habits and eating behavior change. A key disadvantage to this approach stems from treating food, which is a primary reinforcer, similarly to symbolic reinforcers, such as money, that are often used in neuroeconomic paradigms, and thereby ignoring the underlying biology that influences eating behaviors. Future work could disentangle the nuances of food-based from general-purpose decision making. 


\section{Future directions}

As suggested by the emerging reactivity/regulation balance and subjective value literatures, the neural predictors of food consumption and dietary change are most likely more complicated than a traditional dual-process model would suggest. Indeed, there are many other systems known to be involved in food consumption, including identity, ${ }^{81}$ social processes, ${ }^{95}$ and reward learning, ${ }^{96}$ as well as other behavioral processes ${ }^{97}$ Future work should continue to investigate the important roles these processes play in food consumption and dietary change in typical populations.

In particular, a clear next step is further investigation into contextual influences such as broad cultural factors, socioeconomic status (SES), and family/household norms. These factors may act to constrain and/or moderate the magnitude of the brain-as-predictor effects reviewed here, as well as provide situational specificity of these effects. For example, much of the neuroimaging work done to date has used a majority Caucasian sample with high access to education and financial resources. ${ }^{98,99}$ How the findings reviewed here generalize to other populations remains an open question. Further, we have yet to see how the food environment affects eating behavior and dietary change, as the relative availability of different food types (i.e., healthy vs. unhealthy) should directly affect the valuation of different food items. As food environment, dietary behaviors, and weight are closely associated with socioeconomic status, it follows that these all may covary meaningfully with SES. The direction of these relationships is still undetermined, however. It may be that, in a food environment where healthier food options such as fresh produce are less plentiful, these items attain higher value; or, it may be that these items lose value by virtue of being unfamiliar. Similarly, these processes may also work on a smaller, household-by-household level, wherein food values vary based on their representation within a family.

As a key goal in health neuroscience is to identify factors that confer risk and protection, another important avenue for future research is to study eating behavior from a developmental perspective. Dietary habits are shaped throughout childhood and adolescence, 100 and while children do not typically have control over their diets, adolescents have increasing autonomy in dietary choices, ${ }^{101}$ as well as greater capacity for self-regulation compared to children. ${ }^{102}$ As such, adolescence may be a particularly advantageous period for intervention. Currently, there is a substantial literature on the relationships between reactivity to food stimuli and individual differences in retrospective food intake, ${ }^{103,104}$ body mass index (BMI),${ }^{10,105-107}$ body composition, ${ }^{107}$ satiety, ${ }^{108,109}$ familial risk for obesity, 110,111 and self-reported measures of pathological eating habits ${ }^{112,113}$ in children and adolescents. Several recent studies have also focused on the relationship between regulation, including inhibitory control ${ }^{114}$ and cognitive reappraisal, ${ }^{53,60,115}$ and individual differences in BMI. Additional work has investigated the relationship between decision making and retrospective food consumption ${ }^{116}$ and BMI. ${ }^{117}$ However, none of these studies assessed concurrent or prospective food consumption. To further our understanding of the factors that confer risk for and protection against unhealthy dietary habits and obesity, we hope that future developmental work will include measures of food consumption and dietary change. 


\section{Conclusion}

One of the holy grails in health neuroscience is prospective prediction of outcomes. A tool that could indicate whether someone will get screened for colorectal cancer, exercise more, or change his or her eating patterns would be transformative for disease prevention. In this article, we presented evidence from health neuroscience in support of the potential for human functional neuroimaging to one day produce such a tool. While it may never be feasible to use neuroimaging on an individual basis, associations uncovered by health neuroscience research may be translatable on a larger scale. However, before that vision can be realized, the field will need a practical model (or set of models) of the mechanisms of eating behavior change. We summarized evidence that food reactivity, regulation, and valuation are mechanisms of eating behavior and that their neural indices may be predictive of change. Therefore, we argue that reactivity, regulation, and valuation are promising targets for interventions to change eating patterns. It is our plan to conduct translational neuroscience studies that simultaneously test these theoretical models and promote behavior change in real world settings, and it is our hope that others will find this review helpful for doing the same.

\section{Acknowledgments}

This work was supported by NIH grants AG048840, CA175241, and CA211224 to E.T.B. N.R.G. and E.T.B. conceived of the present review. N.R.G. and J.S.M. further developed the ideas in the manuscript. N.R.G. was the primary writer. D.C., N.R.G., and J.S.M. made the figures. All authors contributed writing and edits to the final manuscript. E.T.B. is manager of Berkman Consultants, LLC, a consulting firm that specializes in motivation and behavior change.

\section{References}

1. Erickson KI, Creswell JD, Verstynen TD, et al. Health Neuroscience: Defining a New Field. Curr Dir Psychol Sci. 2014; 23:446-453. [PubMed: 25844028]

2. Tang DW, Fellows LK, Small DM, et al. Food and drug cues activate similar brain regions: A metaanalysis of functional MRI studies. Physiol Behav. 2012; 106:317-324. [PubMed: 22450260]

3. van der Laan LN, de Ridder DTD, Viergever MA, et al. The first taste is always with the eyes: a meta-analysis on the neural correlates of processing visual food cues. Neuroimage. 2011; 55:296303. [PubMed: 21111829]

4. Stice E, Spoor S, Bohon C, et al. Relation of reward from food intake and anticipated food intake to obesity: A functional magnetic resonance imaging study. J Abnorm Psychol. 2008; 117:924-935. [PubMed: 19025237]

5. Giuliani NR, Tomiyama AJ, Mann T, et al. Prediction of daily food intake as a function of measurement modality and restriction status. Psychosom Med. 2015; 77:583-590. [PubMed: 25984820]

6. Berkman ET, Falk EB. Beyond brain mapping: Using neural measures to predict real-world outcomes. Curr Dir Psychol Sci. 2013; 22:45-50. [PubMed: 24478540]

7. Gabrieli JDE, Ghosh SS, Whitfield-Gabrieli S. Prediction as a humanitarian and pragmatic contribution from human cognitive neuroscience. Neuron. 2015; 85:11-26. [PubMed: 25569345]

8. Demos KE, Heatherton TF, Kelley WM. Individual differences in nucleus accumbens activity to food and sexual images predict weight gain and sexual behavior. J Neurosci. 2012; 32:5549-5552. [PubMed: 22514316]

9. Stice E, Yokum S, Blum K, et al. Weight gain is associated with reduced striatal response to palatable food. J Neurosci. 2010; 30:13105-13109. [PubMed: 20881128] 
10. Yokum S, Ng J, Stice E. Attentional bias to food images associated with elevated weight and future weight gain: An fMRI study. Obesity. 2011; 19:1775-1783. [PubMed: 21681221]

11. Malik VS, Willett WC, Hu FB. Global obesity: trends, risk factors and policy implications. Nat Rev Endocrinol. 2012; 9:13-27. [PubMed: 23165161]

12. Schwingshackl L, Hoffmann G. Diet Quality as Assessed by the Healthy Eating Index, the Alternate Healthy Eating Index, the Dietary Approaches to Stop Hypertension Score, and Health Outcomes: A Systematic Review and Meta-Analysis of Cohort Studies. J Acad Nutr Diet. 2015; 115:780-800. [PubMed: 25680825]

13. Gnagnarella P, Gandini S, La Vecchia C, et al. Glycemic index, glycemic load, and cancer risk: A meta-analysis. Am J Clin Nutr. 2008; 87:1793-1801. [PubMed: 18541570]

14. Norat T, Lukanova A, Ferrari P, et al. Meat consumption and colorectal cancer risk: Dose-response meta-analysis of epidemiological studies. Int J Cancer. 2002; 98:241-256. [PubMed: 11857415]

15. Allen NE, Key TJ, Appleby PN, et al. Animal foods, protein, calcium and prostate cancer risk: the European Prospective Investigation into Cancer and Nutrition. Br J Cancer. 2008; 98:1574-1581. [PubMed: 18382426]

16. Donaldson MS. Nutrition and cancer: A review of the evidence for an anti-cancer diet. Nutr J. 2004; 3:19. [PubMed: 15496224]

17. Hofmann W, Schmeichel BJ, Baddeley AD. Executive functions and self-regulation. Trends Cogn Sci. 2012; 16:174-180. [PubMed: 22336729]

18. Metcalfe J, Mischel W. A hot/cool-system analysis of delay of gratification: dynamics of willpower. Psychol Rev. 1999; 106:3-19. [PubMed: 10197361]

19. Brocas I, Carrillo JD. Dual-process theories of decision-making: A selective survey. J Econ Psychol. 2014; 41:45-54.

20. Séguin JR, Arseneault L, Tremblay RE. The contribution of "cool" and "hot" components of decision-making in adolescence: Implications for developmental psychopathology. Cogn Dev. 2007; 22:530-543.

21. Deutsch R, Strack F. Duality models in social psychology: From dual processes to interacting systems. Psychol Inq. 2006; 17:166-172.

22. Boswell RG, Kober H. Food cue reactivity and craving predict eating and weight gain: a metaanalytic review. Obes Rev. 2016; 17:159-177. [PubMed: 26644270]

23. Kringelbach ML. The human orbitofrontal cortex: linking reward to hedonic experience. Nat Rev Neurosci. 2005; 6:691-702. [PubMed: 16136173]

24. Berridge KC. "Liking" and "wanting" food rewards: Brain substrates and roles in eating disorders. Physiol Behav. 2009; 97:537-550. [PubMed: 19336238]

25. Berridge KC. Food reward: Brain substrates of wanting and liking. Neurosci Biobehav Rev. 1996; 20:1-25. [PubMed: 8622814]

26. Soussignan R, Schaal B, Boulanger V, et al. Orofacial reactivity to the sight and smell of food stimuli. Evidence for anticipatory liking related to food reward cues in overweight children. Appetite. 2012; 58:508-516. [PubMed: 22245131]

27. Morewedge CK, Huh YE, Vosgerau J. Thought for food: Imagined consumption reduces actual consumption. Science (80-). 2010; 330:1530-1533.

28. Delgado MR. Annals of the New York Academy of Sciences. Blackwell Publishing Inc; 2007. Reward-related responses in the human striatum; 70-88.

29. Robbins TW, Everitt BJ. Functions of dopamine in the dorsal and ventral striatum. Semin Neurosci. 1992; 4:119-127.

30. Smeets PAM, Charbonnier L, van Meer F, et al. Food-induced brain responses and eating behaviour. Proc Nutr Soc. 2012; 71:511-520. [PubMed: 22931854]

31. Frankort A, Roefs A, Siep N, et al. Neural predictors of chocolate intake following chocolate exposure. Appetite. 2015; 87:98-107. [PubMed: 25528694]

32. Mehta S, Melhorn SJ, Smeraglio A, et al. Regional brain response to visual food cues is a marker of satiety that predicts food choice. Am J Clin Nutr. 2012; 96:989-999. [PubMed: 22990034] 
33. Nolan-Poupart S, Veldhuizen MG, Geha P, et al. Midbrain response to milkshake correlates with ad libitum milkshake intake in the absence of hunger. Appetite. 2013; 60:168-174. [PubMed: 23064394]

34. Kroemer NB, Sun X, Veldhuizen MG, et al. Weighing the evidence: Variance in brain responses to milkshake receipt is predictive of eating behavior. Neuroimage. 2016; 128:273-283. [PubMed: 26724781]

35. Berridge KC, Ho CY, Richard JM, et al. The tempted brain eats: Pleasure and desire circuits in obesity and eating disorders. Brain Res. 2010; 1350:43-64. [PubMed: 20388498]

36. Havermans RC. "You Say it's Liking, I Say it's Wanting ...”. On the difficulty of disentangling food reward in man. Appetite. 2011; 57:286-294. [PubMed: 21635928]

37. Polk SE, Schulte EM, Furman CR, et al. Wanting and liking: Separable components in problematic eating behavior? Appetite. 2017; 115:45-53. [PubMed: 27840087]

38. Lawrence NS, Hinton EC, Parkinson JA, et al. Nucleus accumbens response to food cues predicts subsequent snack consumption in women and increased body mass index in those with reduced self-control. Neuroimage. 2012; 63:415-422. [PubMed: 22776461]

39. Falk EB, Berkman ET, Whalen D, et al. Neural activity during health messaging predicts reductions in smoking above and beyond self-report. Heal Psychol. 2011; 30:177-185.

40. Burger KS, Berner LA. A functional neuroimaging review of obesity, appetitive hormones and ingestive behavior. Physiol Behav. 2014; 136:121-127. [PubMed: 24769220]

41. Koole S. The psychology of emotion regulation: An integrative review. Cogn Emot. 2009; 23:4-41.

42. Duckworth AL. The significance of self-control. Proc Natl Acad Sci. 2011; 108:2639-2640. [PubMed: 21300864]

43. Nederkoorn C, Houben K, Hofmann W, et al. Control yourself or just eat what you like? Weight gain over a year is predicted by an interactive effect of response inhibition and implicit preference for snack foods. Heal Psychol. 2010; 29:389-393.

44. Tsukayama E, Toomey SL, Faith MS, et al. Self-control as a Protective Factor Against Overweight Status in the Transition From Childhood to Adolescence. Arch Pediatr Adolesc Med. 2010; 164:631-635. [PubMed: 20603463]

45. de Ridder DTD, Lensvelt-Mulders G, Finkenauer C, et al. Taking Stock of Self-Control. Personal Soc Psychol Rev. 2012; 16:76-99.

46. Kishinevsky FI, Cox JE, Murdaugh DL, et al. FMRI reactivity on a delay discounting task predicts weight gain in obese women. Appetite. 2012; 58:582-592. [PubMed: 22166676]

47. Giuliani NR, Berkman ET. Craving Is an Affective State and Its Regulation Can Be Understood in Terms of the Extended Process Model of Emotion Regulation. Psychol Inq. 2015; 26:48-53. [PubMed: 25780321]

48. Giuliani NR, Calcott RD, Berkman ET. Piece of cake. Cognitive reappraisal of food craving. Appetite. 2013; 64:56-61. [PubMed: 23313699]

49. Giuliani NR, Mann T, Tomiyama AJ, et al. Neural systems underlying the reappraisal of personally craved foods. J Cogn Neurosci. 2014; 26:1390-402. [PubMed: 24392892]

50. Hollmann M, Hellrung L, Pleger B, et al. Neural correlates of the volitional regulation of the desire for food. Int J Obes. 2011; 36:648-655.

51. Kober H, Mende-Siedlecki P, Kross EF, et al. Prefrontal-striatal pathway underlies cognitive regulation of craving. Proc Natl Acad Sci USA. 2010; 107:14811-14816. [PubMed: 20679212]

52. Siep N, Roefs A, Roebroeck A, et al. Fighting food temptations: The modulating effects of shortterm cognitive reappraisal, suppression, and up-regulation on mesocorticolimbic activity related to appetitive motivation. Neuroimage. 2012; 60:213-220. [PubMed: 22230946]

53. Yokum S, Stice E. Cognitive regulation of food craving: effects of three cognitive reappraisal strategies on neural response to palatable foods. Int J Obes. 2013; 37:1565-1570.

54. Stice E, Yokum S, Burger K, et al. A pilot randomized trial of a cognitive reappraisal obesity prevention program. Physiol Behav. 2015; 138:124-32. [PubMed: 25447334]

55. Wilson GT, Fairburn CG. Cognitive treatments for eating disorders. J Consult Clin Psychol. 1993; 61:261-269. [PubMed: 8473579] 
56. Buhle JT, Silvers JA, Wage TD, et al. Cognitive reappraisal of emotion: A meta-analysis of human neuroimaging studies. Cereb Cortex. 2014; 24:2981-2990. [PubMed: 23765157]

57. Ochsner KN, Gross JJ. The cognitive control of emotion. Trends Cogn Sci. 2005; 9:242-9. [PubMed: 15866151]

58. Ochsner KN, Gross JJ. Cognitive Emotion Regulation: Insights From Social Cognitive and Affective Neuroscience. Curr Dir Psychol Sci. 2008; 17:153-158. [PubMed: 25425765]

59. Ochsner KN, Silvers JA, Buhle JT. Functional imaging studies of emotion regulation: a synthetic review and evolving model of the cognitive control of emotion. Ann N Y Acad Sci. 2012; 1251:E1-24. [PubMed: 23025352]

60. Giuliani NR, Pfeifer JH. Age-related changes in reappraisal of appetitive cravings during adolescence. Neuroimage. 2015; 108:173-181. [PubMed: 25536500]

61. Stice E, Yokum S, Veling H, et al. Pilot test of a novel food response and attention training treatment for obesity: Brain imaging data suggest actions shape valuation. Behav Res Ther. 2017; 94:60-70. [PubMed: 28505470]

62. Chen Z, Veling H, Dijksterhuis A, et al. How does not responding to appetitive stimuli cause devaluation: Evaluative conditioning or response inhibition? J Exp Psychol Gen. 2016; 145:16871701. [PubMed: 27736134]

63. Folkvord F, Veling H, Hoeken H. Targeting implicit approach reactions to snack food in children: Effects on intake. Heal Psychol. 2016; 35:919-922.

64. Houben K, Nederkoorn C, Jansen A. Eating on impulse: The relation between overweight and food-specific inhibitory control. Obesity. 2014; 22:E6-E8. [PubMed: 24910860]

65. Lawrence NS, Verbruggen F, Morrison S, et al. Stopping to food can reduce intake. Effects of stimulus-specificity and individual differences in dietary restraint. Appetite. 2015; 85:91-103. [PubMed: 25447023]

66. Lawrence NS, O'Sullivan J, Parslow D, et al. Training response inhibition to food is associated with weight loss and reduced energy intake. Appetite. 2015; 95:17-28. [PubMed: 26122756]

67. Veling H, Aarts H, Stroebe W. Using stop signals to reduce impulsive choices for palatable unhealthy foods. Br J Health Psychol. 2013; 18:354-368. [PubMed: 23017096]

68. Veling H, Aarts H, Stroebe W. Stop signals decrease choices for palatable foods through decreased food evaluation. Front Psychol. 2013; 4:875. [PubMed: 24324451]

69. Berkman ET, Burklund L, Lieberman MD. Inhibitory spillover: Intentional motor inhibition produces incidental limbic inhibition via right inferior frontal cortex. Neuroimage. 2009; 47:705712. [PubMed: 19426813]

70. Hendrick OM, Luo X, Zhang S, et al. Saliency Processing and Obesity: A Preliminary Imaging Study of the Stop Signal Task. Obesity. 2012; 20:1796-1802. [PubMed: 21720427]

71. Hofmann W, Friese M, Roefs A. Three ways to resist temptation: The independent contributions of executive attention, inhibitory control, and affect regulation to the impulse control of eating behavior. J Exp Soc Psychol. 2009; 45:431-435.

72. Vainik U, Dagher A, Dubé L, et al. Neurobehavioural correlates of body mass index and eating behaviours in adults: A systematic review. Neurosci Biobehav Rev. 2013; 37:279-299. [PubMed: 23261403]

73. Fregni F, Orsati F, Pedrosa W, et al. Transcranial direct current stimulation of the prefrontal cortex modulates the desire for specific foods. Appetite. 2008; 51:34-41. [PubMed: 18243412]

74. Delgado MR, Gillis MM, Phelps EA. Regulating the expectation of reward via cognitive strategies. Nat Neurosci. 2008; 11:880-881. [PubMed: 18587392]

75. Diekhof EK, Gruber O. When Desire Collides with Reason: Functional Interactions between Anteroventral Prefrontal Cortex and Nucleus Accumbens Underlie the Human Ability to Resist Impulsive Desires. J Neurosci. 2010; 30:1488-1493. [PubMed: 20107076]

76. Lopez RB, Chen PHA, Huckins JF, et al. A balance of activity in brain control and reward systems predicts self-regulatory outcomes. Soc Cogn Affect Neurosci. 2017; 12:832-838. [PubMed: 28158874]

77. Lovic V, Saunders BT, Yager LM, et al. Rats prone to attribute incentive salience to reward cues are also prone to impulsive action. Behav Brain Res. 2011; 223:255-261. [PubMed: 21507334] 
78. Hofmann SG, Heering S, Sawyer AT, et al. How to handle anxiety: The effects of reappraisal, acceptance, and suppression strategies on anxious arousal. Behav Res Ther. 2009; 47:389-94. [PubMed: 19281966]

79. Rangel A, Camerer C, Montague PR. Neuroeconomics: The neurobiology of value-based decisionmaking. Nat Rev Neurosci. 2008; 9:545-556. [PubMed: 18545266]

80. Hare TA, Malmaud J, Rangel A. Focusing attention on the health aspects of foods changes value signals in vmPFC and improves dietary choice. J Neurosci. 2011; 30:11077-11087.

81. Berkman ET, Livingston JL, Kahn LE. Finding The "Self" in Self-Regulation: The Identity-Value Model. Psychol Inq. 2017; 28:77-98.

82. Doucerain M, Fellows LK. Eating right: Linking food-related decision-making concepts from neuroscience, psychology, and education. Mind, Brain, Educ. 2012; 6:206-219.

83. Berkman ET, Hutcherson CA, Livingston JL, et al. Self-Control as Value-Based Choice. Curr Dir Psychol Sci. 2017; 26:422-428. [PubMed: 29335665]

84. Rangel A. Regulation of dietary choice by the decision-making circuitry. Nat Neurosci. 2013; 16:1717-1724. [PubMed: 24270272]

85. Berkman ET. Value-based choice: An integrative, neuroscience-informed model of health goals. Psychol Health. 2017:1-18. [PubMed: 27616462]

86. Krajbich I, Rangel A. Multialternative drift-diffusion model predicts the relationship between visual fixations and choice in value-based decisions. Proc Natl Acad Sci. 2011; 108:13852-13857. [PubMed: 21808009]

87. Hare TA, Camerer CF, Rangel A. Self-control in decision-making involves modulation of the vmPFC valuation system. Science. 2009; 324:646-648. [PubMed: 19407204]

88. Tang DW, Fellows LK, Dagher A. Behavioral and neural valuation of foods is driven by implicit knowledge of caloric content. Psychol Sci. 2014; 25:2168-2176. [PubMed: 25304885]

89. Genevsky A, Yoon C, Knutson B. When brain beats behavior: Neuroforecasting crowdfunding outcomes. J Neurosci. 2017; 37:1633-16.

90. Doyle JR. Survey of Time Preference, Delay Discounting Models. Judgm Decis Mak. 2013; 8:116-135.

91. Dassen FCM, Houben K, Jansen A. Time orientation and eating behavior: Unhealthy eaters consider immediate consequences, while healthy eaters focus on future health. Appetite. 2015; 91:13-19. [PubMed: 25814191]

92. Gossen HH. The Development of the Laws of Exchange among Men and of the Consequent Rules of Human Action. Cambridge, MA: MIT Press; 1854. 1983

93. Huber J, Payne JW, Puto C. Adding Asymmetrically Dominated Alternatives: Violations of Regularity and the Similarity Hypothesis. J Consum Res. 1982; 9:90.

94. Nook EC, Zaki J. Social norms shift behavioral and neural responses to foods. J Cogn Neurosci. 2015; 27:1412-26.

95. Templeton EM, Stanton MV, Zaki J. Social norms shift preferences for healthy and unhealthy foods. PLoS One. 2016; 11:e0166286. [PubMed: 27861518]

96. Kelley AE. Ventral striatal control of appetitive motivation: Role in ingestive behavior and rewardrelated learning. Neurosci and Biobeh Rev. 2004; 27:765-776.

97. Stice E, Lawrence NS, Kemps E, et al. Training motor responses to food: A novel treatment for obesity targeting implicit processes. Clin Psychol Rev. 2016; 49:16-27. [PubMed: 27498406]

98. Lewinn KZ, Sheridan MA, Keyes KM, et al. Sample composition alters associations between age and brain structure. Nat Commun. 2017; 8:874. [PubMed: 29026076]

99. Henrich J, Heine SJ, Norenzayan A. The weirdest people in the world? Behav Brain Sci. 2010; 33:61-83. [PubMed: 20550733]

100. Birch LL, Fisher JO. Development of eating behaviors among children and adolescents. Pediatrics. 1998; 101:539-549. [PubMed: 12224660]

101. Contento IR, Williams SS, Michela JL, et al. Understanding the food choice process of adolescents in the context of family and friends. J Adolesc Heal. 2006; 38:575-582.

102. Casey BJ. Beyond simple models of self-control to circuit-based accounts of adolescent behavior. Annu Rev Psychol. 2015; 66:295-319. [PubMed: 25089362] 
103. Burger KS, Stice E. Elevated energy intake is correlated with hyperresponsivity in attentional, gustatory, and reward brain regions while anticipating palatable food receipt. Am J Clin Nutr. 2013; 97:1188-1194. [PubMed: 23595877]

104. Burger KS, Stice E. Frequent ice cream consumption is associated with reduced striatal response to receipt of an ice cream-based milkshake. Am J Clin Nutr. 2012; 95:810-817. [PubMed: 22338036]

105. Gearhardt AN, Yokum S, Stice E, et al. Relation of obesity to neural activation in response to food commercials. Soc Cogn Affect Neurosci. 2014; 9:932-938. [PubMed: 23576811]

106. Van Meer F, Van Der Laan LN, Charbonnier L, et al. Developmental differences in the brain response to unhealthy food cues: An fMRI study of children and adults. Am J Clin Nutr. 2016; 104:1515-1522. [PubMed: 27806979]

107. Rapuano KM, Huckins JF, Sargent JD, et al. Individual Differences in Reward and Somatosensory-Motor Brain Regions Correlate with Adiposity in Adolescents. Cereb Cortex. 2016; 26:2602-2611. [PubMed: 25994961]

108. Bruce AS, Holsen LM, Chambers RJ, et al. Obese children show hyperactivation to food pictures in brain networks linked to motivation, reward and cognitive control. Int J Obes. 2010; 34:14941500 .

109. Holsen LM, Zarcone JR, Thompson TI, et al. Neural mechanisms underlying food motivation in children and adolescents. Neuroimage. 2005; 27:669-676. [PubMed: 15993629]

110. Carnell S, Benson L, (Virginia) Chang KY, et al. Neural correlates of familial obesity risk and overweight in adolescence. Neuroimage. 2017; 159:236-247. [PubMed: 28754348]

111. Stice E, Yokum S, Burger KS, et al. Youth at risk for obesity show greater activation of striatal and somatosensory regions to food. J Neurosci. 2011; 31:4360-4366. [PubMed: 21430137]

112. Bohon C. Greater emotional eating scores associated with reduced frontolimbic activation to palatable taste in adolescents. Obesity. 2014; 22:1814-1820. [PubMed: 24715468]

113. Burger KS, Stice E. Relation of dietary restraint scores to activation of reward-related brain regions in response to food intake, anticipated intake, and food pictures. Neuroimage. 2011; 55:233-239. [PubMed: 21147234]

114. Batterink L, Yokum S, Stice E. Body mass correlates inversely with inhibitory control in response to food among adolescent girls. An fMRI study. Neuroimage. 2010; 52:1696-1703. [PubMed: 20510377]

115. Silvers JA, Insel C, Powers A, et al. Curbing craving: behavioral and brain evidence that children regulate craving when instructed to do so but have higher baseline craving than adults. Psychol Sci. 2014; 25:1932-1942. [PubMed: 25193941]

116. He Q, Xiao L, Xue G, et al. Altered dynamics between neural systems sub-serving decisions for unhealthy food. Front Neurosci. 2014; 8:350. [PubMed: 25414630]

117. Mata F, Verdejo-Roman J, Soriano-Mas C, et al. Insula tuning towards external eating versus interoceptive input in adolescents with overweight and obesity. Appetite. 2015; 93:24-30. [PubMed: 25819606] 


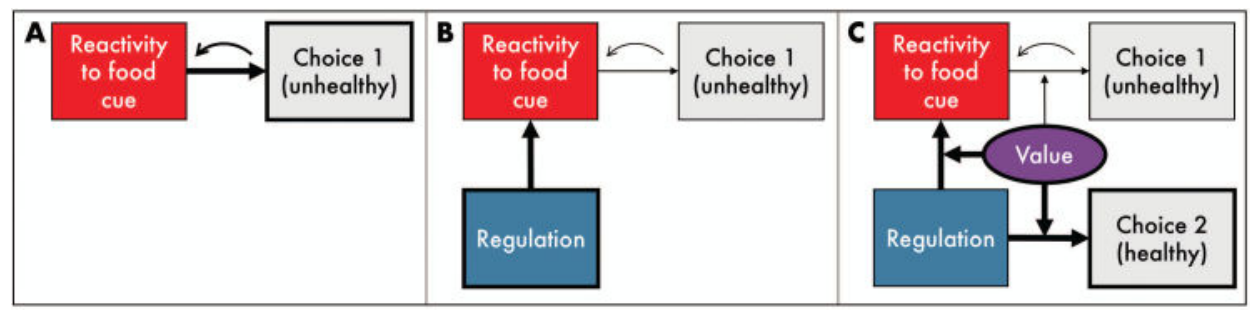

Figure 1.

Proposed framework integrating reactivity, regulation, and value in predicting food choice behaviors. (A) Model of cue-reactivity predicting behavior: reactivity to a desired, unhealthy food cue predicts choice of that food, the consumption of which may then feedback on the reactivity to that cue. (B) Standard model of regulation predicting behavior: cognitive regulation of food cue-reactivity down-regulates reactivity to reduce consumption of the unhealthy food. (C) Integrating subjective value of food choice behaviors: the subjective value that an individual places on individual food options, as well as regulation itself, moderates the relative weights of reactivity and regulation to influence food choice (here, potentiating regulation of the reactivity to the unhealthy food and the value of consuming the healthy food). 


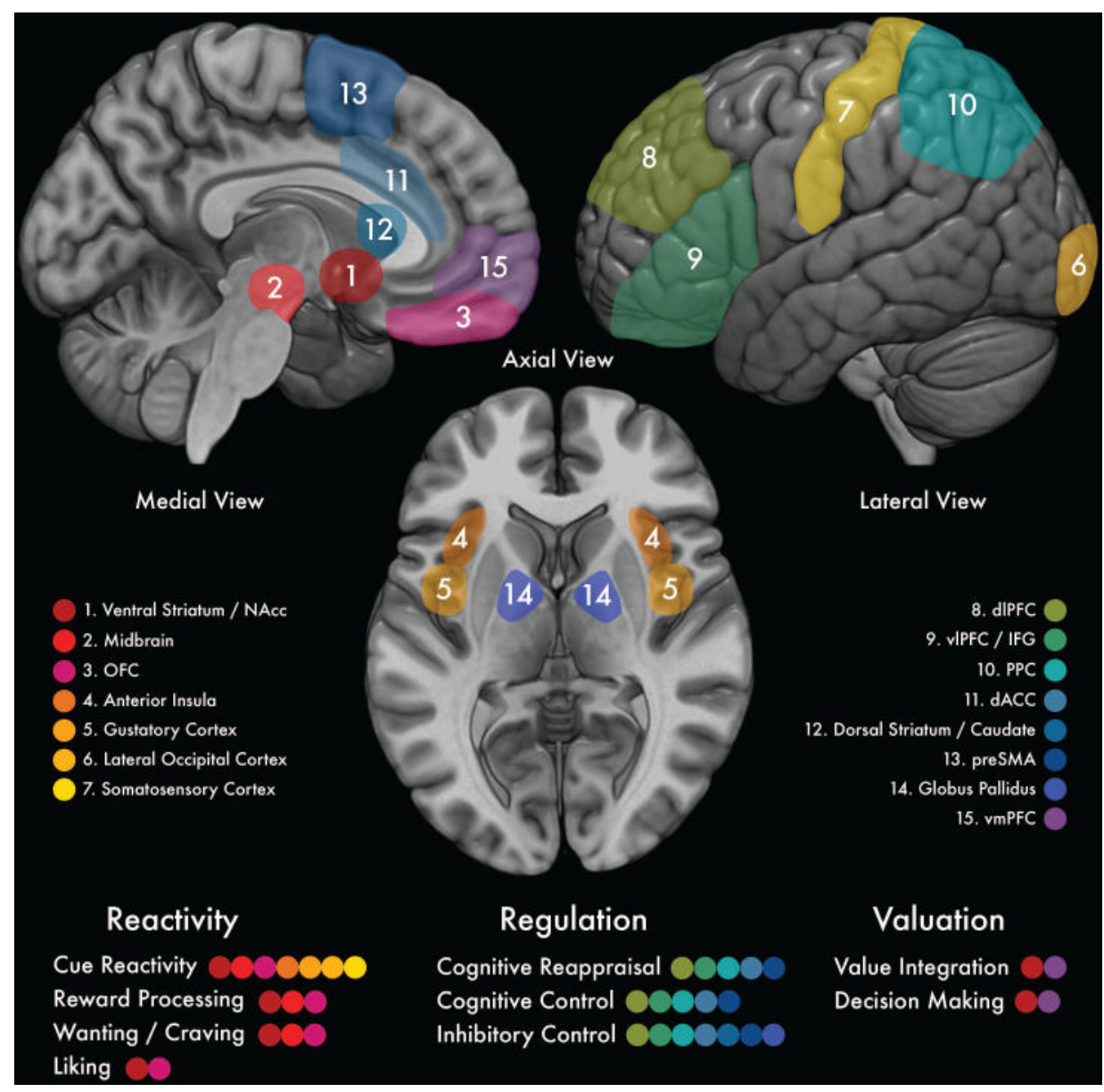

Figure 2.

Map of brain regions commonly recruited during food-related reactivity, regulation, and valuation, and their component processes. $\mathrm{NAcc}=$ nucleus accumbens; $\mathrm{OFC}=$ orbitofrontal cortex; $\mathrm{dlPFC}=$ dorsolateral prefrontal cortex $; \mathrm{vlPFC}=$ ventrolateral prefrontal cortex; IFG $=$ inferior frontal gyrus; $\mathrm{PPC}=$ posterior parietal cortex $\mathrm{dACC}=$ dorsal anterior cingulate cortex ; preSMA = pre-supplementary motor area; $\mathrm{vmPFC}=$ ventromedial prefrontal cortex . 